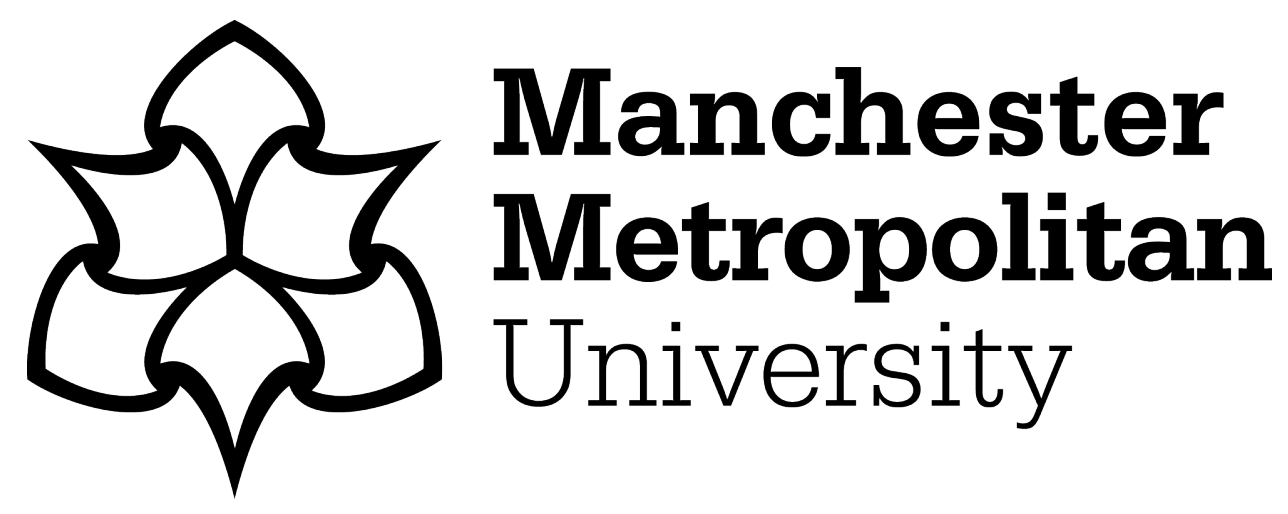

Kislov, R ORCID logoORCID: https://orcid.org/0000-0003-2525-7673, Hodgson, D and Boaden, R (2016) Professionals as knowledge brokers: The limits of authority in healthcare collaboration. Public Administration, 94 (2). pp. 472-489. ISSN 0033-3298

Downloaded from: https://e-space.mmu.ac.uk/624106/

Version: Accepted Version

Publisher: Wiley

DOI: https://doi.org/10.1111/padm.12227

Please cite the published version 


\title{
Professionals as knowledge brokers: The limits of authority in healthcare collaboration
}

\begin{abstract}
Professionals with managerial responsibilities are often seen as natural boundary spanners, brokering knowledge between the professional and managerial domains. However, the tensions implicit in their knowledge brokering activities, especially when the latter are formalized, remain under-researched. Using interviews and observational data, we examine the case of an inter-organizational collaborative research partnership that deployed clinical professionals as designated knowledge brokers across multiple sites. We identify three strategies that such hybrid professionals utilized to surmount challenges associated with knowledge brokering in the fragmented healthcare context: (1) relying on additional boundary 'bridges'; (2) conforming to existing ways of doing things; and (3) shifting from 'facilitating' to 'doing'. An analysis of these strategies highlights the tensions between different dimensions of brokering reinforced by macro-level institutional arrangements, the intertwining of formalized and emergent elements of brokering as a collectively-enacted phenomenon, and the limitations of knowledge brokering professionals arising from their professional expertise and authority.
\end{abstract}

\section{Keywords}

Knowledge brokers; boundary spanners; hybrids; professionals; healthcare

This is the peer reviewed version of the following article: [Kislov, R., Hodgson, D. \& Boaden, R. 2016. Professionals as knowledge brokers: The limits of authority in healthcare collaboration. Public Administration, published online before print on 19/11/2015], which has been published in final form at http://onlinelibrary.wiley.com/doi/10.1111/padm.12227/abstract. This article may be used for non-commercial purposes in accordance with Wiley Terms and Conditions for Self-Archiving. 


\section{Introduction}

Knowledge brokers are individuals that bridge a gap in social structure and help knowledge flow across that gap by facilitating interaction, exchange of ideas and negotiation of meaning across previously separated practices, groups and organizations (Wenger 1998; Burgess and Currie 2013). Much of knowledge brokering work within and across organizations remains informal, unrecognized and embedded in local contexts (Currie and White 2012) but public and private sector organizations increasingly acknowledge the potential of deliberately-created knowledge brokering roles in enabling the coordination, collaboration and integration of different agencies and professional groups (Ward et al. 2009; Chew et al. 2013). Institutionalized knowledge brokering can be seen as a form of intentional boundary spanning which is based upon an expectation that the brokered knowledge will be used in the policy and practice decisions (Mitton et al. 2007), ultimately influencing the opinions and actions of knowledge recipients (Contandriopoulos et al. 2010).

This paper extends the analysis of knowledge brokering beyond the boundaries of a single organization or profession and offers an exploration of quasi-managerial practitioners (Causer and Exworthy 1998, p. 84) who have no formal supervisory or resource allocation duties but act as formally designated knowledge brokers in a fragmented context of inter-organizational collaboration. Whilst professional hybrids are often seen as natural boundary spanners (Ferlie et al. 1996; Fitzgerald and Ferlie 2000; Llewellyn 2001), our analysis highlights that reliance on hybrid roles to make an impact on the knowledge and learning processes can be accompanied by unwanted consequences stemming not only from contextual constraints but also, paradoxically, from a high level of professional expertise and authority. Furthermore, we demonstrate how the strategies deployed by brokers to mitigate their lack of power in a fragmented context may lead to the prioritization of more formalized aspects of knowledge brokering over its facilitative dimension, further limit brokers' managerial authority, and eventually result in the reinforcement of existing institutional patterns. 
The first section provides an overview of the literature on professionals as knowledge brokers, reflecting on their hybrid nature. The second section explores the challenges experienced by hybrid knowledge brokers in healthcare. The procedures of data collection and analysis are outlined in the Case and method section. The Findings section describes the strategies deployed by knowledge brokering professionals to mitigate their lack of power in a constraining context. The Discussion reflects on the theoretical implications of these strategies while the Conclusion summarizes the key messages, practical implications and limitations of the study.

\section{Professionals as designated knowledge brokers}

Knowledge brokers are individuals who, by participating in several communities of practice, enable translation, coordination and alignment between different perspectives and facilitate transactions between previously separated practices (Brown and Duguid 1991; Wenger 1998). They provide continuity of action and interaction at the boundaries, i.e. 'sites of difference' emerging through local negotiations and subsequently objectified in the form of social entities (Abbott 1995; Kislov 2014). In many cases, the brokerage of practice-based knowledge through situated interaction would be an intrinsic, and often unrecognized, part of normal, day-to-day work practice (cf. 'internal' knowledge brokering in Currie and White 2012, p. 1335). We highlight our focus on designated (also referred to as institutionalized, dedicated, or nominated) knowledge brokers, i.e. those who have an explicit remit in knowledge brokering which constitutes their 'core' responsibility and takes up a significant proportion of their time (Knight and Lightowler 2010). Designated knowledge brokers can often be found in fragmented, multi-organizational contexts, such as inter-organizational information systems development projects (Levina and Vaast 2005), voluntary public-private partnerships (Noble and Jones 2006) and university-industry collaborations (Knight and Lightowler 2010), including collaborative research partnerships bringing together producers and users of research (Harvey et al. 2011; Rowley et al. 2012; Chew et al. 2013). Their knowledge brokering remit is often reflected in their official role titles, examples including knowledge transfer associates 
(Harvey et al. 2011), diffusion fellows (Rowley et al. 2012) and knowledge exchange officers (Knight and Lightowler 2010).

In highly professionalized contexts, such as healthcare, knowledge brokering functions can be assigned to hybrid practitioners who move away from a purely professional role to assume managerial responsibilities while continuing their professional practice to maintain legitimacy with their peers (Fitzgerald et al. 2013). Such hybrids include both managing professionals, who have a formally designated supervisory or resource allocation responsibilities, and quasi-managerial professionals, who either fulfil such roles informally or have responsibilities in other areas of management, such as performance measurement, project management or handling external relations on behalf of an organization (Causer and Exworthy 1998). Hybrid professionals use their inbetween positions to support innovation and change through connecting, recombining and translating managerial and professional knowledge across different individuals and groups within and outside an organization (Fitzgerald 1994; Fitzgerald and Ferlie 2000; Burgess and Currie 2013). Retaining membership, identification and accountability with clinical communities of practice, hybrids are perceived by their clinical colleagues as more credible to broker knowledge than managers without a clinical background (Fitzgerald and Ferlie 2000; Llewellyn 2001; Burgess and Currie 2013).

Activities performed by designated knowledge brokers can be clustered along the following three dimensions (Ward et al. 2009; Turnhout et al. 2013): (1) information management, which is underpinned by a linear view of knowledge sharing and involves supplying relevant expertise to knowledge users, often through the codification of tacit knowledge and its presentation to knowledge recipients in an appropriate format; (2) linkage and exchange, involving interaction with different groups, contextualization of knowledge in their local work practices and mediation between different perspectives; and (3) facilitation, which implies helping relevant groups translate the situated knowledge into action and thus create sustainable solutions for the problems at hand. 
The boundary spanning work of formally designated knowledge brokers involves a blend of these functions tailored to specific contexts (Chew et al. 2013) and incorporates a constant interplay between tacit and explicit knowledge. ${ }^{1}$ Explicit, articulated, codified knowledge (often sourced from outside an organization) needs to be fed into organizational members, applied in practice and made tacit. At the same time, tacit knowledge brokered through social interaction and action often has to be codified to become transferrable to new generations of organizational members (Crossan et al. 1999; Tsoukas and Vladimirou 2001).

Knowledge brokering professionals embody collaborative (Adler et al. 2008), or connective (Noordegraaf et al. 2014) professionalism, whereby collaboration is not restricted to maintaining sheltered jurisdictions with peer professionals but increasingly embraces other professional and managerial groups which are seen as interdependent and interconnected. ${ }^{2}$ This interconnectedness implies the collective and situated nature of knowledge brokering (Currie and White 2012). Waring et al. $(2013$, p. 85$)$ show that it is rare for any one individual to fulfil the full range of knowledge brokering activities, especially when the relationships are constrained by the formalized role specifications, and that 'broker chains' can improve the sharing of knowledge between communities. Effectiveness of designated knowledge brokering professionals also rests on their ability to participate, at least peripherally, in the actual practices they are brokering knowledge into and on their recognition as legitimate negotiators in these practices (Levina and Vaast 2005). This process often faces a number of challenges which will be examined in more detail in the following section.

\section{Challenges for knowledge brokering professionals in}

\section{healthcare}

There is often a mismatch between the actual practices of institutionalized knowledge brokering and expectations others have of these roles (Levina and Vaast 2005; Mørk et al. 2012). Brokers are expected to identify, select and obtain information from the environment and efficiently transmit it 
within and across the organizations according to needs, but practical difficulties may arise from the competition between different sources (e.g. scientific, clinical or managerial) and types (e.g. tacit or explicit) of knowledge as well as between opinions, preferences and interests of multiple knowledge users (Contandriopoulos et al. 2010). In case of knowledge brokering professionals, these issues can be aggravated by the ambiguous and contested nature of the hybrid position itself, which "both represents the professional agenda and embodies its disciplining by the managerial one', thus threatening the stability and sustainability of the role (Ferlie et al. 1996, p. 194). Furthermore, the work performed by knowledge brokering professionals can be complicated by the tension between the performance-orientated facet of policy, which encourages the utilization of codified knowledge to control professionals, and a more recent emphasis on inter-agency collaboration, partnership and horizontal knowledge sharing in the form of linkage and exchange and facilitation (Currie et al. 2007; Waring and Currie 2009).

Another set of challenges arises from a complex landscape of practice in which these hybrids operate (Kislov et al. 2011) and the existing power arrangements within that landscape (Currie et al. 2007). Senior clinician-managers, such as medical directors, report the lack of managerial autonomy and authority to determine priorities for clinicians (Hoque et al. 2004) and can struggle managing relationships with their peers (Fitzgerald 1994). Legitimacy to broker knowledge may be limited to the hybrid's own profession, community of practice and/or organization, with much less knowledge brokering to higher status professionals, such as doctors, or to external organizations (Currie and White 2012; Burgess and Currie 2013). Formally designated knowledge brokers placed in a fragmented and multilevel arena might also (at least initially) lack an in-depth contextual knowledge of the actors involved and the ties between them, which can only be acquired in practice through cross-boundary experience, networking and collaborative working (Williams 2012). This can be compounded by the lack of an institutionalized career path and lack of engagement of host organizations in knowledge mobilization projects (Currie et al. 2007). 
A number of strategies potentially mitigating the challenges above have been described. ${ }^{3}$ Senior managing professionals often rely on subtle mechanisms of influencing through collegiality, reciprocation and normative values, rather than autocracy, when managing peer professionals (Fitzgerald and Ferlie 2000; Sheaff et al. 2003; Hoque et al. 2004; Numerato et al. 2012). For lowerstatus managing professionals, it is argued, power status differentials may be successfully mediated by their proximity to frontline practice and a high degree of connectedness with others within an organization (Burgess and Currie 2013). Chew and colleagues (2013) have shown that role ambiguity associated with a formally designated full-time knowledge brokering role can be mitigated by privileging one side of the boundary over the other; by relying on social support within emerging communities of practice of knowledge intermediaries; and by using positional ambiguity to craft the intermediary role from the 'bottom up' and find novel opportunities. At the same time, these strategies are contingent on organizational flexibility, have questionable sustainability in the long term and can potentially threaten the equanimity of a knowledge brokering role.

Overall, whilst challenges associated with the pursuit of hybrid professional roles are well documented (Fitzgerald 1994; Fitzgerald and Ferlie 2000; Llewellyn 2001; Sheaff et al. 2003; Hoque et al. 2004), there is lack of theoretical understanding of how institutionalized knowledge brokering influences the actual knowledge processes unfolding in practice. First, the tensions implicit in the day-to-day tactics of designated knowledge brokers in complex organizational settings remain under-researched (with a recent exception of Chew et al. 2013), including the relationship between the (possibly conflicting) dimensions of knowledge brokering. Second, the interaction between institutionalized knowledge brokering and other organizational arrangements, both formal and informal, requires more attention (Foss et al. 2010). Finally, whilst hybrid roles are seen as an organizational panacea for reform in professionalized contexts (Croft et al. 2015), it is useful to expand the exploration of their limitations beyond the micro-processes of role and identity transition (Kippist and Fitzgerald 2009; Croft et al. 2015; Spyridonidis et al. 2015) by focusing on the 
potential negative consequences of actions undertaken by hybrids when discharging their professional duties.

This study aims to address these gaps by presenting a case of an inter-organizational collaborative partnership deploying clinicians in a formalized knowledge brokering role located within multiple sets of co-existing and overlapping boundaries (Hernes 2004; Kislov et al. 2012), including organizational boundaries and those between different 'domains of practice' (Mørk et al. 2012, p. 268), such as science, medicine, management and policy. It is guided by the following two research questions. What strategies do knowledge brokering professionals deploy to alleviate the challenges associated with fulfilling a hybrid role in a multiprofessional and multi-organizational landscape? What are the implications of these strategies for theoretical understanding of institutionalized knowledge brokering as deliberate and action-oriented boundary spanning embedded in broader organizational and institutional context?

\section{Case and method}

The study was conducted in a large-scale UK-based collaborative partnership (hereafter referred to as 'Collaboration') between a university and healthcare organizations, which included a number of (largely self-contained) disease-specific projects focused on implementing the findings from existing health research in day-to-day clinical practice. Halfway through the five-year period of funding (2009-2013), the leadership of the Collaboration decided to employ clinical professionals as parttime designated knowledge brokers bringing their expertise in a specific clinical domain and professional legitimacy to existing project teams. ${ }^{4}$ Apart from knowledge brokers, each project team included a clinical lead, a management academic and several managers who supported knowledge brokers in their frontline boundary spanning activities in the National Health Service (NHS) organizations, where research evidence was to be implemented. Evidence underpinning the clinical aspects of the projects was determined by nationally adopted clinical guidelines; the format of the projects was co-developed by the members of the project teams, including the knowledge brokers; 
the frontline knowledge brokering activities were mainly driven by knowledge brokering professionals themselves.

We used a single embedded case study methodology and focused on three projects ('Heart, 'Kidney' and 'Brain'), selected based on the following criteria: (1) part-time secondment of at least two NHS clinicians (hereafter referred to as 'secondees') into designated knowledge brokering roles; (2) involvement of the secondees in both clinical and non-clinical aspects of project delivery; and (3) knowledge brokering as an explicit part of the project as well as of secondees' core responsibilities. Whilst each project worked with a different group of primary care practices and deployed different secondees, all of them shared a management team represented by non-clinical managers. The characteristics of the projects are presented in Table 1 . It is important to note for subsequent analysis that regardless of their organizational affiliations as clinicians, most of the secondees' knowledge brokering activities were performed in multiple primary care organizations ('general practices') taking part in the projects. Although internal to the NHS as a whole, the secondees were therefore often external to the organizations they were brokering knowledge into.

Table 1

Within the case, a purposive sampling strategy was used, with 57 research participants drawn from the three projects and the management team to represent different sectors (primary, community and secondary care) and occupational groups (doctors, nurses, care coordinators, managers, etc. ${ }^{5}$ ) (Table 2). Semi-structured interviews served as the main method of data collection and were conducted in two stages. The first stage (March 2012-March 2013), which was mostly projectspecific, explored the secondees' roles in different settings, mapped out the processes of institutionalized knowledge brokering, and induced a list of theoretical propositions to guide further data collection and analysis. In the second stage (March-October 2013), centred on the identification of common themes across projects, these propositions were tested to uncover the strategies used 
by the secondees to perform their knowledge brokering roles in the multiprofessional and multiorganizational context. Interviews lasted from 30 to 95 minutes, with an average length of around one hour. Some of the secondees and members of the management team were interviewed twice. For the purpose of triangulation, the interviews were supplemented by direct observation (14 hours) of team meetings, educational sessions and practice visits which involved the secondees, as well as by numerous informal face-to-face conversations with research participants. ${ }^{6}$

Table 2

Interviews were digitally recorded and transcribed verbatim; interview transcripts and observation field notes were coded and analysed with the aid of NVivo software. The process of coding was organized in three rounds. In the first round, each of the three project-specific datasets were coded separately and template analysis (King 2004) was deployed to systematize the codes into three initial templates, which allowed a sense of distinctiveness of each of the three subcases to be gained. The second round of coding, which was conducted across subcases, aggregated previously identified contextual factors (e.g. lack of seniority, performance management, teamwork, etc.) with a number of emerging categories (e.g. adapting to the knowledge patterns within a general practice, 'internal and 'external boundary bridges', 'facilitation', etc.). Producing the final template was accompanied by matrix analysis (Nadin and Cassell 2004) to compare and contrast the three subcases. Finally, in an iterative process of refining categories, detecting patterns and developing explanations, existing codes and categories were transformed into three main themes (relying on additional boundary 'bridges'; conforming to the existing ways of doing things; and shifting from 'facilitating' to 'doing'), which reflected the emergent strategies of knowledge brokering relevant for all of the three subcases. Member checking ${ }^{7}$ and triangulation of data obtained from different groups and by different methods were used to ensure the validity of research findings. 


\section{Findings}

\section{Relying on additional boundary bridges}

In all of the three projects the knowledge brokering professionals mainly focused on those aspects of work that required clinical skills, such as auditing the general practice registers, coordinating the patient journey between different providers or helping the primary care staff improve the management of chronic disease patients. 'Knowledge' that they were brokering was not, however, limited to explicit research evidence in the form of clinical guidelines. In most cases, it represented 'bundled action proposals' (Contandriopoulos et al. 2010, p. 464), intertwining a set of actionable ideas about how clinical guidelines (scientific knowledge) could be applied in practice (clinical knowledge), underpinned by the tacit understanding of the healthcare context (contextual knowledge). At the same time, most of the generic coordination activities were undertaken by the Collaboration's management team, who had expertise in project management and quality improvement and were often seen as more knowledgeable than the secondees about the organizational landscape of primary care. The managers thus complemented the knowledge brokering role of the secondees:

\footnotetext{
Quite often in a feedback session I might have some knowledge in relation to a clinical picture, but then [the manager] might have some information that's from a non-clinical side that I might not have been aware of and also... if neither of us know an answer, she'll help you do some digging as well and she'll feed back to the practice. (S2; Heart) ${ }^{8}$
}

The secondees were occasionally seen as lacking seniority and thus having limited influence within their own organizations or localities, which also required the involvement of the management team and was critically perceived by some of the managers:

...I would confess to... probably taking a back seat a little bit and observing and letting [the managers]... do all the talking [in the meetings with senior people]... (S3; Brain) 
...I don't know if [the secondee] could actually set something up on her own and go in to negotiate with people at the $\mathrm{CCG}^{9}$ level... She wouldn't have the influence or the credibility to set up and deliver projects on a bigger scale... That seems like an awful waste of resource from the [Collaboration's] point of view, to have somebody babysitting a secondee all the time... (M1; Management team)

There was also a perceived need across all of the projects to identify and collaborate with a number of key individuals from within the primary care practices. In a different way to the Collaboration managers, these people also acted as 'bridges' between the secondee and the rest of the practice, by ensuring that the knowledge and skills brought in by the secondee became assimilated within the organization. Ideally, these boundary bridges would include representation from different professional groups, i.e. medics, nurses and administrators, but in some of the practices the communication was going through one person, which sometimes made the transfer of knowledge to other professional groups problematic and thus undermined local sustainability of change introduced by the secondees' knowledge brokering activities:

\footnotetext{
...Having a clinical link and a sort of admin link and probably a link with one of the practice nurses... within the surgery seems to be the best model to have... And there's a couple of surgeries where that's not the case, and that probably works less well... The communication with [one of the surgeries]... is difficult because it all goes through one person who isn't a clinician and it's hard to know how much information that's sent to her is disseminated. (S5; Brain)

...If the wrong GP got [blood test results], they didn't get actioned or worked on at all... If anyone had any queries they would sort of send them all to me and then I would go to [the secondee]... (CC2; Kidney)
}

To sum up, whilst the secondees remained the main knowledge brokering actors bridging the organizational (between the Collaboration and general practices) and professional boundaries (between their own clinical fields and the fields of knowledge users), their activities were significantly influenced by additional boundary 'bridges' linking them with wider professional and organizational groups at different levels of the hierarchy. 


\section{Conforming to the existing ways of doing things}

In all of the projects, a lot of face-to-face knowledge sharing took place at meetings conducted within primary care organizations, in which the secondees actively participated. Many of them highlighted the importance of 'being flexible', which meant accepting and making the best use of the procedures offered by the general practices, rather than trying to impose their views on who should be present in the meetings and how they should be organized:

You have to be flexible, you have to go with their way of working; otherwise they just won't want the meetings to take place... You can't just go in with a blueprint of how it's going to work... (S5; Brain)

...In one instance we did feedback to the advanced nurse practitioner at a practice, we had asked the GPs and other people to be there, but it was just this advanced practitioner in the end, and it was very good, we went through everything, but we were almost relying on the fact that that person disseminated to the rest of the practice then. (S1; Heart)

Another important strategy utilized by the secondees was linking the knowledge they were trying to broker with the national performance management system for the primary care sector in England, the Quality and Outcomes Framework $(\mathrm{QOF})^{10}$. Those secondees who were new to primary care quickly had to learn that helping the practices get extra QOF points (and thus increase their financial income) could be a strong motivator both for 'selling' the project to participating organizations and for overcoming their resistance:

\footnotetext{
...We have tried to show the GPs who've shown initial reluctance what we've managed to achieve by coding all their patients correctly which will ultimately not only make much better for patient care but will also improve their practice figures. ...GPs and practice managers are very keen on their QOF figures. (S10; Kidney)
}

At the same time, conforming to the QOF had a number of influences on the overall focus and direction of the projects and tended to shift the secondees' knowledge brokering activities towards 'QOF-able' aspects of work. This resulted, for instance, in privileging the auditing phase of the Heart 
and Kidney projects, aiming to identify new patients and thus meet performance targets, over the feedback phase, aiming to help the practices improve the clinical care of these patients according to clinical guidelines:

...One GP said to me last week, 'There's no incentive for me to do heart failure reviews'. People will get better care but he was talking in terms of remuneration because of the QOF points and things that they get... As part of the QOF they have to have people with heart failure and they have to have had a diagnosis and then they have to be on ACE inhibitors and beta blockers. It doesn't go much further than that... (S1; Heart)

...[The practices] are probably motivated by the case finding because... what they've done when we've given them the results, they've tended to look at the case finding and work on that first because the case finding will add the patients to the register and increase the prevalence. So they've tended to work on that. (M2; Management team)

Such conformance significantly shaped the content of 'action proposals' brokered by the secondees. Robustness of the research evidence and clinical authority of the brokers proved to be insufficient for engaging the general practices if the proposed activities were to involve a radical alteration of the usual organizational routines or did not explicitly link with the adopted performance indicators.

\section{Shifting from 'facilitating' to 'doing'}

At the outset, the secondees were expected to 'transfer' their knowledge and skills to primary care organizations and support them in undertaking appropriate actions to improve the quality of care for the relevant groups of patients. In reality, in all of the projects the relationship between 'facilitating', i.e. helping others to implement change (Harvey et al. 2002), and 'doing', i.e. implementing change for others, turned out to be more complicated, with a general tendency for the designated knowledge brokers to become more involved in the actual processes of implementation than initially envisaged: 
We have been given the repeated message that achievement against objectives is the be-all and endall, and to this end, our secondees have been encouraged and pushed towards doing rather than facilitating to achieve these outcomes. (M7; Management team)

The degree of the shift from 'facilitating' to 'doing' varied across the projects, which may be explained by project-specific contextual differences (Table 3). In the Heart project, the secondees were heavily involved in auditing the registers, which was enabled by the fact that they possessed specialist clinical expertise required for undertaking this aspect of performance measurement and were seen as clinically legitimate by all professional groups in primary care. The audit was conducted without much involvement from the primary care staff who were later expected to act upon its results:

[The Heart secondees] were explicitly hired for their specialist knowledge... I would never, ever, ever call them a [Collaboration] facilitator... They're less facilitating perhaps than doing the work, because of the nature of the project, and they are doing the work for the practices, so they are auditing; whereas in [Kidney] work, the practice audits with the support of [the Collaboration]. (M8; Management team)

The facilitation aspect of knowledge brokering was indeed more pronounced in the work of the Kidney project secondees, although they often chose to do more than they had initially envisaged, especially when the practice staff were not given protected time to work on the project, expressed little interest in implementation or needed encouragement:

\footnotetext{
Sometimes, especially with workloads, it's been very, very difficult for [the practices]; I've actually gone in and done some work with them and also on my own, working through the registers to try and help them tidy up their lists and to generate patients that need reviews... (S10; Kidney)
}

In the Brain project, the main responsibility of the secondees was to provide clinical coordination between primary, secondary and community care and generate concerted action aiming to improve the provision of healthcare services. Although the ultimate responsibility for undertaking these 
actions lay with the primary care staff and/or community-based care coordinators, the secondees were under pressure to expand their role towards doing more work for the practices in order to build better relationship with the primary care staff and help them meet their targets:

...The restriction of having a [secondee] that, yes, links into the rest of the mental health teams, but isn't specifically there to do that job... is slightly frustrating... (GP6; Brain)

...One of the problems is that [the practices] perceive we're going in and doing something that's useful for us but they're not getting anything in return. So, I'm trying to offer things that are useful to them in return, even perhaps when it's slightly above and beyond the remit of the project as a way of forming relationships. (S5; Brain)

Table 3

Doing some work for the practices was often presented as a way to create a favourable atmosphere for knowledge sharing. At the same time, a high level of the brokers' involvement in the process of implementation inevitably shifted their attention away from such aspects of knowledge brokering as facilitation and linkage and exchange, potentially undermining practice-based learning and capability development within primary care organizations.

\section{Discussion}

We have described three broad interconnected strategies that designated knowledge brokers utilized in the fragmented healthcare landscape. The first strategy entails the transfer of some of the knowledge brokering responsibilities, such as facilitation and 'linkage and exchange', to other clinicians and managers involved in the knowledge mobilization projects alongside the hybrids. These individuals acted as boundary bridges, which could be external or internal in relation to the healthcare organizations the knowledge brokers were working with. The external boundary bridges, such as managers from the Collaboration's management team, were often perceived as having more 
managerial authority than the secondees. The internal boundary bridges, on the other hand, were instrumental in brokering knowledge between the secondees and their own uniprofessional and multiprofessional communities of practice (Kislov et al. 2012). Both groups of boundary bridges compensated for the secondees' lack of managerial authority, social capital and contextual knowledge. However, the designated knowledge brokers had limited influence on selecting the boundary bridges and often had to make best use of those members of the primary care organizations who were self-nominated or appointed by the organizational leaders but had limited authority within the organization and/or were not ideally suited for fulfilling the boundary spanning role. Whilst internal boundary bridges can act as peer opinion leaders adapting exogenous knowledge to local circumstances (Locock et al. 2001), we show that their sanctioned authority to translate knowledge into action can be limited by their lower status in local hierarchies, strong intraorganizational boundaries and an overall deprioritization of knowledge sharing in a performanceoriented climate.

The second strategy is conformance to the format of boundary interactions that suit the preferences of the powerful individuals and groups within primary care practices, tailoring the objectives, procedures and content of knowledge mobilization projects to the targets specified by the performance measurement system. Tapping onto the existing intra-organizational routines can be a way of alleviating resistance to change and embedding knowledge introduced by the knowledge brokering professionals while QOF can act as a boundary object helping to align the perspectives on multiple communities of practice and translate knowledge into collective action (Kislov et al. 2011). At the same time, in most practices the knowledge brokers could do relatively little (except, perhaps, for some backstage discussions) to alter organizational routines that were dysfunctional and impeded knowledge sharing. Those project components that required a significant change in day-today local practice and/or were not aligned with the financial incentives of the QOF were more likely to be marginalized in the process of translating knowledge into action even if seen as beneficial for healthcare outcomes. The conformity of knowledge brokering professionals may, at least partially, 
be explained by their lower position in a hierarchy compared to doctors, which resonates with previous observations that nursing managers are more likely to buy into managerial goals than are medical managers (Hoque et al. 2004). In addition, the QOF can be seen as a natural continuation of the evidence-based medicine movement which originated from within the medical profession and is thus less likely to be perceived as an instrument of managerial control by clinicians (Cheraghi-Sohi and Calnan 2013).

Finally, the third strategy denotes an increasing involvement of the secondees in the activities lying beyond their designated knowledge brokering remit and often entails involvement in the actual 'doing' or implementation of change in the participating organizations. In some cases 'doing favours' to the local staff may be interpreted as an exercise of 'soft' influence aimed at building good working relationships and inducing reciprocation (Sheaff et al. 2003). In some practices, however, doing work for the staff becomes the way to achieve the objectives of a knowledge mobilization project, especially when the local system of additional boundary bridges is not effective. In such cases, designated knowledge brokers are at risk of being seen as an 'extra pair of hands' provided by an external project, with their knowledge having a relatively low impact on local organizational routines, capacity development and sustainability of change. As shown in Table 3, the degree of the shift from 'facilitating' to 'doing' differed across projects and was contingent on a number of projectspecific factors. It was the highest in the case where project leaders lacked experience in implementation science and/or service improvement; where the participating practices did not receive financial remuneration for their participation in the project which would enable them to allocate protected time to project work; where the project had originally been designed around the notion of knowledge codification; and where the knowledge brokers possessed highly specialized, as opposed to generalist, professional expertise.

The strategies deployed by designated knowledge brokers reveal a number of broader theoretical insights. First, our findings reveal a tension between different dimensions of institutionalized 
knowledge brokering. Whilst organizational learning literature maintains that institutionalization of knowledge normally takes place after it becomes interpreted and embedded in the local group-level practices (Crossan et al. 1999), we show a potential for the marginalization of 'facilitation' in the contexts where other forms of brokering (such as information management) or practices located outside the brokering remit (such as 'doing') are perceived as less resource-intensive and less contingent on local cooperation but can still produce results satisfying the performance objectives. Not only were we unable to find evidence of local resistance to information management as a form of managerial control (Waring and Currie 2009), but the pressure to focus on this dimension often came from practitioners into whom knowledge was being brokered. While it has been argued that controlling the content of shared knowledge might negatively influence its perceived local relevance (Agterberg et al. 2010), our findings suggest that a strong link between the 'action proposal' being brokered and performance targets can make the former appear relevant for both broader organizational needs and local practices. Furthermore, it is often not the type or the source of knowledge embedded in the 'action proposal' but the (perceived) implications of the latter for local routines that determine its inclusion or exclusion in the inherently political process of institutionalized knowledge brokering.

Second, our findings enhance a theoretical understanding of knowledge brokering as a collective phenomenon (Currie and White 2012), responding to the call to 'look into how brokers combine and work together across organizational boundaries' (Waring et al. 2013, p. 86). We highlight the utilization of additional boundary bridges as a mechanism converting the hybrids' emerging social capital into a strategic influence and describe a potential configuration of an emerging 'broker chain' (Waring et al. 2013) in a multi-organizational and multiprofessional context. The composition of the chain, consisting of a designated knowledge broker and two emergent types of additional boundary spanners, leads us to question the dichotomy between the external and internal knowledge brokering, whereby the former refers to the brokering of (formal) knowledge from outside the organization and the latter denotes the sharing of (tacit) knowledge at a local level (Currie and White 
2012). We suggest that while the initial source of knowledge (often combining the tacit and the explicit components) may indeed originate from outside the organization, its successful local assimilation is only possible when this external knowledge is spread within the organization through internal knowledge brokering embedded in collective practice. This can involve boundary spanners emerging locally as well as designated knowledge brokers working across organizations (the latter may be external to an organization as a whole but internal to the professional communities of practice cutting across organizational boundaries) (also see Brown and Duguid 1991).

Third, our findings shed new light on the limitations of quasi-managerial hybrids as designated knowledge brokers. Most of extant literature tends to see hybrids' professional knowledge and skills as an important source of legitimacy and authority enabling their boundary spanning function. This study shows that, paradoxically, professional authority can sometimes become an impediment to a successful realization of all dimensions of knowledge brokering. This is well illustrated by the Heart project, where the brokers with the high level of specialist skills and professional authority remained relatively disengaged from facilitating practice-based learning and situated interaction (Table 3). In addition, the managerial legitimacy of hybrid brokers can be challenged by non-clinical managers who do not necessarily see them as legitimate negotiators at the senior level and, as a result, take over the representational function. These processes may further increase professional authority of hybrid clinicians to carry out their professional activities (and to transfer some of the tasks seen as peripheral to their professional expertise to managers) but decrease their managerial authority over financial or organizational decisions which are related to the work of other professionals (Farrell and Morris 2003). This may help explain why, despite the brokers' undisputed clinical expertise, we found more evidence of adjustment, accommodation and reliance on soft influence than attempts to induce the radical renegotiation of the boundaries (cf. boundary-shaking in Balogun et al. 2005, p. 262). Our findings suggest that through their coping strategies the brokers are more likely to reproduce original institutional arrangements than alter the constraining context of action. 


\section{Conclusion}

Formally designated knowledge brokers operating in a multiprofessional and multi-organizational arena mitigate the constraining power of context by transferring some of their knowledge brokering functions to managers and clinicians; by conforming to the local ways of doing things, such as the incorporation of the pay-for-performance system into the core professional work; and by complementing (and even replacing) the situated processes of knowledge brokering by the supply of knowledge and skills to clinicians wishing to achieve their organizational performance objectives. These strategies reveal how, through the agency of knowledge brokers, macro-level institutional arrangements exert influence on the dynamics of knowledge processes unfolding in practice, how the formalized and emergent elements of knowledge brokering as a collectively-enacted phenomenon are intertwined, and how the professional expertise and authority of hybrids can become an impediment to their knowledge brokering function.

Initiatives deploying designated boundary spanning roles could possibly benefit from diversifying the pool of knowledge brokers to include managers, quasi-managerial professionals and professionals with formal managerial responsibilities, and supporting the formation of links between knowledge brokers working at different levels. Since the facilitative dimension of knowledge brokering is at risk of becoming marginalized, it is also crucial to encourage the active involvement of knowledge recipients in the process of organizational change that is supposed to be induced by the mobilized knowledge, which may require amending the local reward systems as well as providing direct remuneration. At the policy level, the discourses of coordination, collaboration and knowledge sharing need to be accompanied by strategies promoting the development of internal capacity of public sector organizations to utilize research evidence, rather than relying on external agencies that have to overcome multiple boundaries to achieve influence within these organizations (Kislov et al. 2014). 
Our findings represent an attempt to identify common themes that reflect the experiences of knowledge brokers across all of the projects and organizations involved in the study. This is why an analysis of variability in micro-level interaction between the designated knowledge brokers and (differentially receptive to change) host organizations was beyond the scope of this paper. Also, since our study only looked at a relatively early stage of the professionals' involvement in institutionalized knowledge brokering, it may well happen that the strategies described here could change over time. A longitudinal exploration of the individual trajectories of hybrid professionals through the ambiguous boundary space between managerialism and professionalism may be a fruitful area of future research. This study has indicated that the legitimacy of knowledge brokers is not limited to the credibility of their professional knowledge or acceptance of their intermediary position; exploring the legitimacy of actions that are induced by brokerage and can differentially affect multiple groups may form another direction of potential empirical enquiry.

Beyond healthcare, our findings may apply to a wide range of professionals who are expected to broker knowledge, influence their peers and drive change in networks and other fragmented contexts involving multiple organizations. Mitigating strategies described here are likely to be generalizable to the groups of quasi-managerial professionals and external consultants, who enjoy professional legitimacy but lack formal authority due to their lower status and/or external position. Finally, insights gained into knowledge brokering as a group phenomenon involving both internal and external dimensions can potentially inform further analyses of collaborative partnerships, knowledge networks and other boundary organizations that have to reconcile the tensions between different types, forms and sources of knowledge held by multiple actors operating in inconsistent policy environments.

\section{Acknowledgements}

This study was funded by the National Institute for Health Research Collaboration for Leadership in Applied Health Research and Care (NIHR CLAHRC) Greater Manchester. The views expressed in this 
article are those of the authors and not necessarily those of the NHS, NIHR or the Department of Health. We would like to thank Lorraine Burey, John Humphreys, Carrie Hunt, Katy Rothwell, Mike Spence and Stephanie Tierney for their contribution to data collection; our research participants for their feedback; and Kathryn Oliver and Anne McBride for their constructive comments on an early version of the manuscript. We are also grateful to Martin Lodge for editorial guidance and to the three anonymous reviewers for helping us significantly improve the paper. 
${ }^{1}$ While the purpose of institutionalized knowledge brokering is sometimes limited to the translation of research evidence, as the preferred form of 'knowledge', into practical action (Mitton et al. 2007; Ward et al. 2009), we follow Contandriopoulos et al. (2010) in adopting a broad view of knowledge, which encompasses all types of information used in practice, and viewing institutionalized knowledge brokering as a set of 'generic processes unrelated to the internal validity of the information exchanged' (ibid., p. 458; emphasis in original).

${ }^{2}$ This focus on establishing continuity of action and interaction across the boundaries (Kislov 2014) conceptually distinguishes knowledge brokering from boundary work (Gieryn 1983) which denotes discourses and practices aimed at establishing epistemic authority of one group over the other(s) in order to monopolize, expand or protect its jurisdiction in a contested field.

${ }^{3}$ Following Mintzberg and Waters (1985, p. 257), we adopt a broad definition of strategies as 'patterns in streams of actions', with a particular interest in emergent strategies, i.e. those realized 'despite, or in the absence of intentions', as opposed to deliberate strategies, which are underpinned by the analytical process of establishing goals and action plans followed by their realization as intended.

${ }^{4}$ Designated knowledge brokers are conceptually different from clinical champions (Hendy and Barlow 2012), project champions (Noble and Jones 2006) and expert opinion leaders (Locock et al. 2001)-established leaders in their organizations and/or communities of practice, who create favourable conditions for boundary spanning, activate the initial stages of innovation and change but do not become intimately involved in the process of implementation itself. By contrast, hybrid knowledge brokers explored by this study worked at the interface between different organizations and professional groups on a daily basis and assumed overall responsibility for translating knowledge into action.

${ }^{5}$ Since the strategies deployed by hybrid professionals in the process of institutionalized knowledge brokering were the main focus of our study, the secondees were naturally seen as key informants. At the same time, we significantly expanded our sample by including the representatives of different groups who were affected by the work of the secondees because we view knowledge brokering as a boundary process in which 'no one operates totally alone, and every individual who brings about some change is embedded in some type of structure, whether overt or covert' (Hernes 2004, p. 27).

${ }^{6}$ Informal conversations were particularly useful in clarifying the details of what has been observed, memberchecking emerging analytical interpretations and, in case of the Collaboration management team members who worked across projects, provided additional insights into similarities and differences between the three subcases.

${ }^{7}$ The emerging findings of the study were presented at one of the Collaboration's management team meetings. Research participants also had an opportunity to provide feedback on the transcripts of their interviews as well as on the first draft of this manuscript. They comments significantly enhanced the factual accuracy and interpretative richness of the account presented in this paper.

${ }^{8}$ The following abbreviations are used to indicate respondents who are quoted in this section: CC - clinical coordinator; GP - general practitioner; M - manager; S - secondee (a hybrid clinician/manager seconded by the Collaboration from a healthcare organization to perform the role of a formally designated knowledge broker).

${ }^{9}$ Clinical Commissioning Groups (CCGs) are groups of general practices responsible for commissioning the majority of health services in England. 
${ }^{10}$ Quality and Outcomes Framework (QOF) is a prescriptive pay-for-performance system designed to standardize the quality of care provision in general medical practice in the United Kingdom (Cheraghi-Sohi and Calnan 2013). 


\section{References}

Abbott, A. 1995. 'Things of Boundaries', Social Research, 62, 4, 857-82.

Adler, P.S., S.-W. Kwon and C. Heckscher. 2008. 'Professional Work: The Emergence of Collaborative Community', Organization Science, 19, 2, 359-76.

Agterberg, M., B. Van Den Hooff, M. Huysman and M. Soekijad. 2010. 'Keeping the Wheels Turning: The Dynamics of Managing Networks of Practice', Journal of Management Studies, 47, 1, 85108.

Balogun, J., P. Gleadle, V.H. Hailey and H. Willmott. 2005. 'Managing Change across Boundaries: Boundary-Shaking Practices', British Journal of Management, 16, 4, 261-78.

Brown, J.S. and P. Duguid. 1991. 'Organizational Learning and Communities-of-Practice: Toward a Unified View of Working, Learning and Innovation', Organization Science, 2, 1, 40-57.

Burgess, N. and G. Currie. 2013. 'The Knowledge Brokering Role of the Hybrid Middle Level Manager: The Case of Healthcare', British Journal of Management, 24, S132-S42.

Causer, G. and M. Exworthy. 1998. 'Professionals as Managers across the Public Sector', in M. Exworthy and S. Halford (eds), Professionals and the New Managerialism in the Public Sector. Buckingham: Open University Press, pp. 83-101.

Cheraghi-Sohi, S. and M. Calnan. 2013. 'Discretion or Discretions? Delineating Professional Discretion: The case of English Medical Practice', Social Science and Medicine, 96, 52-59.

Chew, S., N. Armstrong and G. Martin. 2013. 'Institutionalising Knowledge Brokering as a Sustainable Knowledge Translation Solution in Healthcare: How Can It Work in Practice?', Evidence \& Policy, 9, 3, 335-51.

Contandriopoulos, D., M. Lemire, J.L. Denis and É. Tremblay. 2010. 'Knowledge Exchange Processes in Organizations and Policy Arenas: A Narrative Systematic Review of the Literature', Milbank Quarterly, 88, 4, 444-83.

Croft, C., G. Currie and A. Lockett. 2015. 'Broken 'Two-Way Windows'? An Exploration of Professional Hybrids', Public Administration, 93, 2, 380-94.

Crossan, M.M., H.W. Lane and R.E. White. 1999. 'An Organizational Learning Framework: From Intuition to Institution', Academy of Management Review, 24, 3, 522-37.

Currie, G., R. Finn and G. Martin. 2007. 'Spanning Boundaries in Pursuit of Effective Knowledge Sharing within Networks in the NHS', Journal of Health Organization and Management, 21, 4/5, 406-17.

Currie, G. and L. White. 2012. 'Inter-Professional Barriers and Knowledge Brokering in an Organizational Context: The Case of Healthcare', Organization Studies, 33, 10, 1333-61.

Farrell, C. and J. Morris. 2003. 'The 'Neo-Bureaucratic' State: Professionals, Managers and Professional Managers in Schools, General Practices and Social Work', Organization, 10, 1, 129-56.

Ferlie, E., L. Ashburner, L. Fitzgerald and A. Pettigrew. 1996. The New Public Management in Action. Oxford: Oxford University Press.

Fitzgerald, L. 1994. 'Moving Clinicians into Management: A Professional Challenge or Threat?', Journal of Management in Medicine, 8, 6, 32-44.

Fitzgerald, L. and E. Ferlie. 2000. 'Professionals: Back to the Future?', Human Relations, 53, 5, 713-39.

Fitzgerald, L., E. Ferlie, G. McGivern and D. Buchanan. 2013. 'Distributed Leadership Patterns and Service Improvement: Evidence and Argument from English Healthcare', The Leadership Quarterly, 24, 1, 227-39.

Foss, N.J., K. Husted and S. Michailova. 2010. 'Governing Knowledge Sharing in Organizations: Levels of Analysis, Governance Mechanisms, and Research Directions', Journal of Management Studies, 47, 3, 455-82.

Gieryn, T.F. 1983. 'Boundary-Work and the Demarcation of Science from Non-Science: Strains and Interests in Professional Ideologies of Scientists', American Sociological Review, 48, 6, 78195. 
Harvey, G., L. Fitzgerald, S. Fielden, A. McBride, H. Waterman, D. Bamford, R. Kislov and R. Boaden. 2011. 'The NIHR Collaboration for Leadership in Applied Health Research and Care (CLAHRC) for Greater Manchester: Combining Empirical, Theoretical and Experiential Evidence to Design and Evaluate a Large-Scale Implementation Strategy', Implementation Science, 6, 96.

Harvey, G., A. Loftus-Hills, J. Rycroft-Malone, A. Titchen, A. Kitson, B. McCormack and K. Seers. 2002. 'Getting Evidence into Practice: The Role and Function of Facilitation', Journal of Advanced Nursing, 37, 6, 577-88.

Hendy, J. and J. Barlow. 2012. 'The Role of the Organizational Champion in Achieving Health System Change', Social Science and Medicine, 74, 3, 348-55.

Hernes, T. 2004. 'Studying Composite Boundaries: A Framework of Analysis', Human Relations, 57, 1, 9-29.

Hoque, K., S. Davis and M. Humphreys. 2004. 'Freedom to Do What You Are Told: Senior Management Team Autonomy in an NHS Acute Trust', Public Administration, 82, 2, 355-75.

King, N. 2004. 'Using Templates in the Thematic Analysis of Text', in C. Cassell and G. Symon (eds), Essential Guide to Qualitative Methods in Organizational Research. London: SAGE Publications, pp. 256-70.

Kippist, L. and A. Fitzgerald. 2009. 'Organisational Professional Conflict and Hybrid Clinician Managers: The Effects of Dual Roles in Australian Health Care Organisations', Journal of Health Organization and Management, 23, 6, 642-55.

Kislov, R. 2014. 'Boundary Discontinuity in a Constellation of Interconnected Practices', Public Administration, 92, 2, 307-23.

Kislov, R., G. Harvey and K. Walshe. 2011. 'Collaborations for Leadership in Applied Health Research and Care: Lessons from the Theory of Communities of Practice', Implementation Science, 6 , 64.

Kislov, R., K. Walshe and G. Harvey. 2012. 'Managing Boundaries in Primary Care Service Improvement: A Developmental Approach to Communities of Practice', Implementation Science, 7, 97.

Kislov, R., H. Waterman, G. Harvey and R. Boaden. 2014. 'Rethinking Capacity Building for Knowledge Mobilisation: Developing Multilevel Capabilities in Healthcare Organisations', Implementation Science, 9, 166.

Knight, C. and C. Lightowler. 2010. 'Reflections of 'Knowledge Exchange Professionals' in the Social Sciences: Emerging Opportunities and Challenges for University-Based Knowledge Brokers', Evidence \& Policy, 6, 4, 543-56.

Levina, N. and E. Vaast. 2005. 'The Emergence of Boundary Spanning Competence in Practice: Implications for Implementation and Use of Information Systems', MIS Quarterly, 29, 2, 33563.

Llewellyn, S. 2001. 'Two-Way Windows': Clinicians as Medical Managers', Organization Studies, 22, 4, 593-623.

Locock, L., S. Dopson, D. Chambers and J. Gabbay. 2001. 'Understanding the Role of Opinion Leaders in Improving Clinical Effectiveness', Social Science and Medicine, 53, 6, 745-57.

Mintzberg, H. and J.A. Waters. 1985. 'Of Strategies, Deliberate and Emergent', Strategic Management Journal, 6, 3, 257-72.

Mitton, C., C.E. Adair, E. McKenzie, S.B. Patten and B.W. Perry. 2007. 'Knowledge Transfer and Exchange: Review and Synthesis of the Literature', Milbank Quarterly, 85, 4, 729-68.

Mørk, B.E., T. Hoholm, E. Maaninen-Olsson and M. Aanestad. 2012. 'Changing Practice through Boundary Organizing: A Case from Medical R\&D', Human Relations, 65, 2, 263-88.

Nadin, S. and C. Cassell. 2004. 'Using Data Matrices', in C. Cassell and G. Symon (eds), Essential Guide to Qualitative Methods in Organizational Research. London: SAGE Publications, pp. 271-87.

Noble, G. and R. Jones. 2006. 'The Role of Boundary-Spanning Managers in the Establishment of Public-Private Partnerships', Public Administration, 84, 4, 891-917. 
Noordegraaf, M., M. Van Der Steen and M. Van Twist. 2014. 'Fragmented or Connective Professionalism? Strategies for Professionalizing the Work of Strategists and Other (Organizational) Professionals', Public Administration, 92, 1, 21-38.

Numerato, D., D. Salvatore and G. Fattore. 2012. 'The Impact of Management on Medical Professionalism: A Review', Sociology of Health and Illness, 34, 4, 626-44.

Rowley, E., R. Morriss, G. Currie and J. Schneider. 2012. 'Research into Practice: Collaboration for Leadership in Applied Health Research and Care (CLAHRC) for Nottinghamshire, Derbyshire, Lincolnshire (NDL)', Implementation Science, 7, 40.

Sheaff, R., A. Rogers, S. Pickard, M. Marshall, S. Campbell, B. Sibbald, S. Halliwell and M. Roland. 2003. 'A Subtle Governance: 'Soft' Medical Leadership in English Primary Care', Sociology of Health and IIIness, 25, 5, 408-28.

Spyridonidis, D., J. Hendy and J. Barlow. 2015. 'Understanding Hybrid Roles: The Role of Identity Processes Amongst Physicians', Public Administration, 93, 2, 395-411.

Tsoukas, H. and E. Vladimirou. 2001. 'What Is Organizational Knowledge?', Journal of Management Studies, 38, 7, 973-93.

Turnhout, E., M. Stuiver, J. Klostermann, B. Harms and C. Leeuwis. 2013. 'New Roles of Science in Society: Different Repertoires of Knowledge Brokering', Science and Public Policy, 40, 3, 35465.

Ward, V., A. House and S. Hamer. 2009. 'Knowledge Brokering: The Missing Link in the Evidence to Action Chain?', Evidence \& Policy, 5, 3, 267-79.

Waring, J. and G. Currie. 2009. 'Managing Expert Knowledge: Organizational Challenges and Managerial Futures for the UK Medical Profession', Organization Studies, 30, 7, 755-78.

Waring, J., G. Currie, A. Crompton and S. Bishop. 2013. 'An Exploratory Study of Knowledge Brokering in Hospital Settings: Facilitating Knowledge Sharing and Learning for Patient Safety?', Social Science and Medicine, 98, 79-86.

Wenger, E. 1998. Communities of Practice: Learning, Meaning and Identity. Cambridge: Cambridge University Press.

Williams, P. 2012. Collaboration in Public Policy and Practice: Perspectives on Boundary Spanners. Bristol: The Policy Press. 


\section{Tables}

\section{TABLE 1 Projects}

\begin{tabular}{|c|c|c|c|}
\hline & Heart & Kidney & Brain \\
\hline Aim(s) of the project & $\begin{array}{l}\text { To improve primary care } \\
\text { practitioners' knowledge } \\
\text { about the diagnosis and } \\
\text { management of heart } \\
\text { failure and to increase its } \\
\text { recorded prevalence on } \\
\text { practice registers }\end{array}$ & $\begin{array}{l}\text { To reduce the gap between } \\
\text { the recorded and estimated } \\
\text { prevalence of chronic } \\
\text { kidney disease (CKD) and to } \\
\text { improve the management } \\
\text { of blood pressure in CKD } \\
\text { patients }\end{array}$ & $\begin{array}{l}\text { To develop an integrated } \\
\text { service user pathway } \\
\text { supporting the prevention, } \\
\text { diagnosis and management } \\
\text { of physical health problems } \\
\text { in people with severe } \\
\text { mental illness (SMI) }\end{array}$ \\
\hline $\begin{array}{l}\text { Duration of the current } \\
\text { phase of the project }\end{array}$ & $\begin{array}{l}\text { February } 2012 \text { - November } \\
2013\end{array}$ & $\begin{array}{l}\text { March } 2011 \text { - November } \\
2013\end{array}$ & July 2012 - December 2013 \\
\hline Organizations involved & 40 general practices & 31 general practices & $\begin{array}{l}5 \text { general practices and } 1 \\
\text { hospital }\end{array}$ \\
\hline Number of secondee posts & 4 & 3 & 2 \\
\hline $\begin{array}{l}\text { Secondees' clinical } \\
\text { occupation }\end{array}$ & Specialist nurses & Practice nurses & $\begin{array}{l}\text { A nurse and an } \\
\text { occupational therapist }\end{array}$ \\
\hline $\begin{array}{l}\text { Secondees' main place of } \\
\text { work }\end{array}$ & Secondary care & Primary care & Secondary care \\
\hline $\begin{array}{l}\text { Secondees' knowledge } \\
\text { brokering role(s) }\end{array}$ & $\begin{array}{l}\text { Performing skills audit, } \\
\text { register verification and } \\
\text { case finding in primary care } \\
\text { practices; feeding back the } \\
\text { results to primary care } \\
\text { staff; facilitating the } \\
\text { changes in day-to-day } \\
\text { clinical practice }\end{array}$ & $\begin{array}{l}\text { Providing help to primary } \\
\text { care staff with data } \\
\text { searches, teamwork } \\
\text { development and guideline } \\
\text { use; acting as a conduit for } \\
\text { knowledge sharing between } \\
\text { practices; facilitating the } \\
\text { changes in day-to-day } \\
\text { clinical practice }\end{array}$ & $\begin{array}{l}\text { Liaising between primary } \\
\text { and secondary care; helping } \\
\text { the primary and community } \\
\text { care staff make joint action } \\
\text { plans for the physical health } \\
\text { management of SMI } \\
\text { patients; searching, } \\
\text { analysing and presenting } \\
\text { the evidence }\end{array}$ \\
\hline
\end{tabular}


TABLE 2 Research participants

\begin{tabular}{|l|l|l|l|l|l|}
\hline & Heart & Kidney & Brain & $\begin{array}{l}\text { Management } \\
\text { team }\end{array}$ & Total \\
\hline Secondees & 4 & 3 & 2 & 1 & 10 \\
\hline GPs & 5 & 5 & 5 & - & 15 \\
\hline Practice nurses & 3 & 4 & 2 & - & 9 \\
\hline Practice/Trust managers & 2 & 2 & 5 & - & 9 \\
\hline Healthcare assistants & - & 2 & - & - & 2 \\
\hline Clinical/care coordinators & - & 1 & 1 & - & 2 \\
\hline Managers & - & - & - & 9 & 9 \\
\hline Researchers & - & - & - & 1 & 1 \\
\hline Total & $\mathbf{1 4}$ & $\mathbf{1 7}$ & $\mathbf{1 5}$ & $\mathbf{1 1}$ & $\mathbf{5 7}$ \\
\hline
\end{tabular}




\section{TABLE 3 Contextual differences between the projects and their influence on the shift from 'facilitating' to 'doing'}

\begin{tabular}{|c|c|c|c|}
\hline & Heart & Kidney & Brain \\
\hline Setup of the project & $\begin{array}{l}\text { Secondary care based } \\
\text { secondees with specialist } \\
\text { clinical skills brokering } \\
\text { knowledge into primary } \\
\text { care organizations }\end{array}$ & $\begin{array}{l}\text { Primary care based } \\
\text { secondees with } \\
\text { generalist clinical skills } \\
\text { brokering knowledge } \\
\text { into primary care } \\
\text { organizations }\end{array}$ & $\begin{array}{l}\text { Secondary care based } \\
\text { secondees brokering } \\
\text { knowledge between } \\
\text { primary and secondary } \\
\text { care }\end{array}$ \\
\hline Project leadership & $\begin{array}{l}\text { Clinical academic on a } \\
\text { joint appointment } \\
\text { between a university and } \\
\text { an NHS Trust with little } \\
\text { previous expertise in } \\
\text { implementation science } \\
\text { or quality improvement }\end{array}$ & $\begin{array}{l}\text { Jointly lead by a clinician } \\
\text { and a social science } \\
\text { academic, both with a } \\
\text { special interest in } \\
\text { implementation science } \\
\text { and quality improvement }\end{array}$ & $\begin{array}{l}\text { Predominantly led by the } \\
\text { Collaboration's } \\
\text { management team } \\
\text { (including a quality } \\
\text { improvement } \\
\text { researcher) }\end{array}$ \\
\hline $\begin{array}{l}\text { Financial incentivization } \\
\text { for the participating } \\
\text { general practices }\end{array}$ & None & $\begin{array}{l}\text { In March } 2011 \text { - March } \\
2012 \text {, all but one of the } \\
\text { practices received } \\
\text { funding from the } \\
\text { Collaboration. No } \\
\text { funding was provided to } \\
\text { the practices joining the } \\
\text { project from April } 2012 \\
\text { onwards. }\end{array}$ & None \\
\hline $\begin{array}{l}\text { Prioritized dimension of } \\
\text { knowledge brokering in } \\
\text { the beginning of the } \\
\text { project }\end{array}$ & $\begin{array}{l}\text { Information } \\
\text { management }\end{array}$ & Facilitation & Linkage and exchange \\
\hline $\begin{array}{l}\text { Prioritization of 'doing' } \\
\text { over 'facilitation' } \\
\text { throughout the course of } \\
\text { the project }\end{array}$ & $\begin{array}{l}\text { 'Audit' increasingly seen } \\
\text { as the key activity, with } \\
\text { 'facilitation' limited to } \\
\text { one-off (interactive) } \\
\text { feedback sessions and } \\
\text { (didactic) educational } \\
\text { events }\end{array}$ & $\begin{array}{l}\text { Decreasing emphasis on } \\
\text { facilitation in 2012-2013, } \\
\text { often explained by the } \\
\text { limited capacity of } \\
\text { primary care clinicians to } \\
\text { engage with the project } \\
\text { in the absence of } \\
\text { financial incentivization }\end{array}$ & $\begin{array}{l}\text { 'Doing favours' by the } \\
\text { secondees seen as } \\
\text { 'building relationships' } \\
\text { with the practices, the } \\
\text { degree of the shift being } \\
\text { less pronounced than in } \\
\text { the other two projects- } \\
\text { probably, due to the } \\
\text { focus on 'linkage and } \\
\text { exchange' }\end{array}$ \\
\hline
\end{tabular}

